\title{
Determination of Synthetic Ferric Chelates Used as Fertilizers by Liquid Chromatography- Electrospray/Mass Spectrometry in Agricultural Matrices
}

\author{
Ana Álvarez-Fernández, ${ }^{*}$ Irene Orera, ${ }^{*}$ Javier Abadía, \\ and Anunciación Abadía \\ Plant Nutrition Department, Estación Experimental de Aula Dei, Consejo Superior de Investigaciones \\ Científicas (CSIC), Zaragoza, Spain
}

A high-performance liquid chromatography-electrospray ionization/mass spectrometry (time of flight) method has been developed for the simultaneous determination of synthetic $\mathrm{Fe}(\mathrm{III})$-chelates used as fertilizers. Analytes included the seven major Fe(III)-chelates used in agriculture, Fe(III)-EDTA, Fe(III)-DTPA, Fe(III)-HEDTA, Fe(III)-CDTA, Fe(III)-o,oEDDHA, $\mathrm{Fe}(\mathrm{III})-o, p \mathrm{EDDHA}$, and Fe(III)-EDDHMA, and the method was validated using isotope labeled ${ }^{57} \mathrm{Fe}(\mathrm{III})$-chelates as internal standards. Calibration curves had $\mathrm{R}$ values in the range $0.9962-$ 0.9997. Limits of detection and quantification were in the ranges 3-164 and 14-945 pmol, respectively. Analyte concentrations could be determined between the limits of quantification and $25 \mu \mathrm{M}$ (racemic and meso Fe(III)-o,oEDDHA and Fe(III)-EDDHMA) or $50 \mu \mathrm{M}$ (Fe(III)EDTA, Fe(III)-HEDTA, Fe(III)-DTPA, Fe(III)-CDTA and Fe(III)-o,pEDDHA). The average intraday repeatability values were $\sim 0.5$ and $5 \%$ for retention time and peak area, respectively, whereas the interday repeatability values were $\sim 0.7$ and $8 \%$ for retention time and peak area, respectively. The method was validated using four different agricultural matrices, including nutrient solution, irrigation water, soil solution, and plant xylem exudates, spiked with Fe(III)-chelate standards and their stable isotope-labeled corresponding chelates. Analyte recoveries found were in the ranges $92-101 \%$ (nutrient solution), 89-102\% (irrigation water), $82-100 \%$ (soil solution), and $70-111 \%$ (plant xylem exudates). Recoveries depended on the analyte, with Fe(III)-EDTA and Fe(III)-DTPA showing the lowest recoveries (average values of 87 and $88 \%$, respectively, for all agricultural matrices used), whereas for other analytes recoveries were between 91 and 101\%. The method was also used to determine the real concentrations of Fe(III)-chelates in commercial fertilizers. Furthermore, the method is also capable of resolving two more synthetic Fe(III)-chelates, Fe(III)-EDDHSA and Fe(III)-EDDCHA, whose exact quantification is not currently possible because of lack of commercial standards. (J Am Soc Mass Spectrom 2007, 18, 37-47) (C) 2007 American Society for Mass Spectrometry

$\mathrm{I}$ ron deficiency is a widespread plant nutritional disorder in many areas worldwide [1, 2], causing decreases in the yield and quality of crops [2, 3], and being also a major problem in human nutrition [4]. The use of synthetic Fe(III)-chelates has been proven to be a successful way to provide Fe to plants since the 1950s. In spite of their high cost, fertilizers containing synthetic $\mathrm{Fe}$ (III)-chelates are nowadays commonly used in soilless horticulture as well as in high value, field-grown crops affected by Fe deficiency. Synthetic Fe(III)-chelates used as fertilizers

Published online September 28, 2006

Address reprint requests to Dr. Ana Álvarez-Fernández, Departamento de Nutrición Vegetal, Estación Experimental de Aula Dei, Consejo Superior de Investigaciones Científicas (CSIC), Apdo. 202, 50080 Zaragoza, Spain. E-mail: ana.alvarez@eead.csic.es

* These two authors contributed equally to the present work. are generally derivatives from the family of ethylenediamine-carboxylic acids and include the Fe(III)chelates of ethylenediamine tetraacetic acid (EDTA) (1), diethylenetriamine pentaacetic acid (DTPA) (2), N-(2-hydroxyethyl)ethylenediaminetriacetic acid (HEDTA) (3), ciclohexane-1,2-diaminetetraacetic acid (CDTA) (4), ethylenediamine-N-N'bis(o-hydroxyphenylacetic) acid (o,oEDDHA) (5), ethylenediamine-N(o-hydroxyphenylacetic)- $\mathrm{N}^{\prime}-(p$-hydroxyphenylacetic) acid (o,pEDDHA) (6), ethylenediamine-N-N'bis(2-hydroxy-4-methylphenylacetic) acid (EDDHMA) (7), ethylenediamine-N-N'bis(5-carboxy-2-hydroxyphenylacetic) acid (EDDCHA) (8), and ethylenediamine-N-N'bis(2-hydroxy-5-sulfophenylacetic) acid (EDDHSA) (9) [5]. These compounds can be applied either to the root system (via soil or nutrient solution) or to the plant shoots (via foliar spray or trunk 

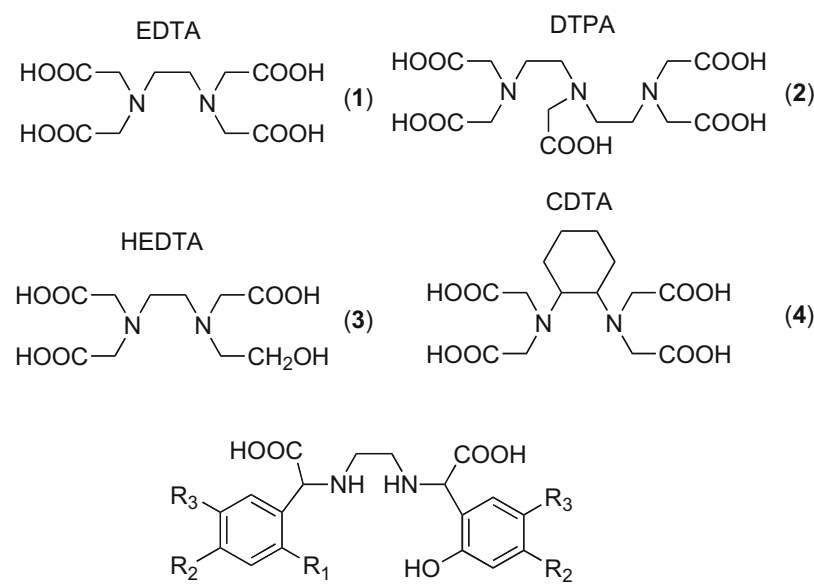

\begin{tabular}{lcccr} 
& $\mathrm{R}_{1}$ & $\mathrm{R}_{2}$ & $\mathrm{R}_{3}$ & \\
\cline { 2 - 4 } o,oEDDHA & $\mathrm{OH}$ & $\mathrm{H}$ & $\mathrm{H}$ & $(5)$ \\
o,pEDDHA & $\mathrm{H}$ & $\mathrm{OH}$ & $\mathrm{H}$ & $(\mathbf{6})$ \\
EDDHMA & $\mathrm{OH}$ & $\mathrm{CH}_{3}$ & $\mathrm{H}$ & $(\mathbf{7})$ \\
EDDCHA & $\mathrm{OH}$ & $\mathrm{H}$ & $\mathrm{COOH}^{(8)}$ \\
EDDHSA & $\mathrm{OH}$ & $\mathrm{H}$ & $\mathrm{HSO}_{3}$ & $(\mathbf{9})$
\end{tabular}

injections). The effectiveness of these compounds is mainly based on their ability to maintain Fe in soluble forms in aerobic environments at the $\mathrm{pH}$ values occurring in soils and plant tissues. These chelates are stable in different $\mathrm{pH}$ ranges, depending on the specific formation constant of each compound and the presence of cations other than Fe(III) [5].

Aminopolycarboxylate chelating agents such as those cited above are currently under scrutiny because of their influence on metal availability and mobility, and in particular because of their high persistence in the environment [6, 7]. However, the mechanisms by which plants take up $\mathrm{Fe}$ from these compounds and the time span of their presence in the plant soil environment system are still a matter of speculation. This is in part due to the lack of analytical methods capable of determining in a specific, reliable, and direct way the very low concentrations of synthetic Fe(III)-chelates that occur in environmental matrices as a result of Fe fertilizer applications. Up to now, methods developed to determine simultaneously several synthetic Fe(III)-chelates have focused mainly on the analysis of simple solutions or commercial fertilizers. Various analytical techniques have been used, such as paper, gel and thin-layer chromatography, electrophoresis, gas chromatography, and high-performance liquid chromatography (HPLC), all of them combined to UV-Vis or atomic absorption spectroscopy [8-13]. All these methods permit reliable detection provided very good chromatographic separations are achieved, using analytical detection techniques with relatively low selectivity. These methods have focused on getting analysis times as short as possible, using $\mathrm{pH}$, buffer, and solvent conditions not affecting Fe-complexation during separation. However, little attention has been given until now to obtain low limits of detection and to avoid interferences in the analysis of real samples, both issues being crucial for quantifying accurately these analytes in complex matrices.

Recently, more selective and sensitive analytical techniques such as inductively coupled mass spectrometry (ICP/MS) and electrospray mass spectrometry (ESI/MS) have been used, permitting to differentiate among different metal species co-eluting within a given chromatographic peak. These techniques allow for the simultaneous determination of several elements (ICP/ MS) or metal-chelate molecules (ESI/MS). ICP/MS is less selective than ESI/MS, but offers higher sensitivity and a larger dynamic range [14]. A problem when using ESI/MS in the analysis of environmental matrices is the poor tolerance to nonvolatile salts, which may reduce sensitivity. Both ICP/MS and ESI/MS are usually coupled to separation techniques, mainly HPLC or capillary electrophoresis, to add molecular specificity (ICP/MS and ESI/MS), and to increase detection limits in salt-rich environmental matrices (ESI/MS). Most of the methods developed so far using these techniques have generally focused on EDTA and DTPA, generally ignoring other chelates and agricultural matrices [6]. For instance, metal-EDTA, -DTPA, and -CDTA complexes, including $\mathrm{Fe}(\mathrm{III})$-EDTA, were determined in nutrient solutions and in ground and surface waters by HPLC-ICP/MS $[15,16]$. ESI/MS has been proven to be a useful tool in the examination of metal-EDTA complexes, including Fe(III)-EDTA [17]. Metal-EDTA complexes were also analyzed by HPLC-ESI/MS in soil solution and plant xylem samples, although Fe(III)EDTA could not be detected because Fe from $\mathrm{Fe}(\mathrm{III})$ EDTA precipitates as an Fe oxide at the very high (9.9) mobile phase $\mathrm{pH}$ used [18]. HPLC-ESI/MS was also used to determine EDTA in industrial effluents by forming the Fe(III)-EDTA complex [19], as well as to determine EDTA and DTPA in influents and effluents of waste water treatment plants by measuring the $[\mathrm{M}-$ $\mathrm{H}]^{-1}$ ions and the corresponding Fe(III) adducts [20]. The chemical characterization of fertilizers containing synthetic Fe(III)-chelates of EDTA, DTPA, EDDHA, EDDHMA, EDDHSA, and EDDCHA has been dealt with using HPLC-ESI/MS [21], although this study provided very limited analytical information, reporting only chromatographic retention times and $\mathrm{m} / \mathrm{z}$ values for the $[\mathrm{M}-\mathrm{H}]^{-1}$ ions of each chelate. Also, HPLCESI/MS was used to characterize Fe(III)-EDDHSA commercial fertilizers, finding a peak with $\mathrm{m} / \mathrm{z}$ attributable to an $\mathrm{Fe}$ (III)-EDDHSA condensation product along with the peak of the active ingredient (Fe(III)-EDDHSA) [22].

The aim of this work was to develop and validate a reliable, direct, and sensitive method to determine, simultaneously, different synthetic Fe(III)-chelates being currently used as fertilizers. The method developed is capable of analyzing the seven major Fe(III)-chelates used in agriculture, which account for a very large portion of the $\mathrm{Fe}(\mathrm{III})$-chelate fertilizer market (247 out of the 263 products in the 2005 market in Spain). The 
method has been validated for use with four agricultural matrices: nutrient solution, irrigation water, soil solution, and plant xylem exudate. Furthermore, the method is also capable of resolving two more synthetic Fe(III)-chelates, Fe(III)-EDDHSA and Fe(III)-EDDCHA, whose exact quantification is not yet possible due to the lack of commercial standards.

\section{Experimental}

\section{Chemicals and Reagents}

All eluents, buffers, and standard solutions were prepared with analytical grade type I water (Milli-Q Synthesis, Millipore, Bedford, MA). Reagent grade glacial acetic acid, hydrochloric acid (35\%), calcium carbonate, and ammonium hydroxide $(25 \%)$ were purchased from Panreac Química S.A. (Barcelona, Spain). Ammonium acetate $(99.99 \%$, Sigma), Li hydroxide monohydrate (99.995\%, Aldrich), methionine (99\%, Sigma), leucine enkephalin (Tyr-Gly-Gly-Phe-Leu, 98\%, Sigma), formic acid (50\%, Fluka), and methanol and 2-propanol (both LC-MS grade, Riedel-de-Haën) were purchased from Sigma-Aldrich (St. Louis, MO). Glutathione (99\%) was purchased from Calbiochem (San Diego, CA).

Chelating agents used were $\mathrm{Na}_{2} \mathrm{H}_{2}$ EDTA.2 $\mathrm{H}_{2} \mathrm{O}$ (99\%, Merck, Barcelona, Spain), DTPA (99\%, Merck), $\mathrm{Na}_{3}$ HEDTA (99\%, Merck), CDTA $\cdot \mathrm{H}_{2} \mathrm{O}$ (99\%, Merck), o,o-EDDHA (98\%, LCG Promochem, Barcelona, Spain), EDDHMA (98\%, LCG Promochem) and Fe(III)-EDDCHA and Fe(III)-EDDHSA (both 5.9\% wt/wt Fe), provided by Professor J. M. García-Mina (Universidad de Navarra, Spain). o,o-EDDHA enriched in racemic form, $o, 0$-EDDHA enriched in meso form, and $o, p$-EDDHA (94.7\%) were kindly provided by Professor J. J. Lucena (Universidad Autónoma de Madrid, Spain). Iron was supplied as iron standard Titrisol (1000 mg Fe in $15 \% \mathrm{HCl}$, Merck). Labeled ${ }^{57} \mathrm{Fe}$ oxide $\left(\mathrm{Fe}_{2} \mathrm{O}_{3}, 98 \% \mathrm{Fe}\right.$, $95.06 \%{ }^{57} \mathrm{Fe}$ ) was obtained from Cambridge Isotope Laboratories (Andover, MA).

\section{Standard Preparations}

Solutions for tuning the mass spectrometer were (1) 10 $\mathrm{mM} \mathrm{LiOH}, 0.2 \%$ (vol/vol) formic acid and 50\% (vol/ vol) 2-propanol, and (2) $1 \mu \mathrm{M}$ leucine-enkephalin, 20 $\mu \mathrm{M}$ methionine, $5 \mu \mathrm{M}$ glutathione, $0.1 \%$ (vol/vol) formic acid and 50\% (vol/vol) methanol.

Stock solutions of ${ }^{57} \mathrm{Fe}-$ labeled $(0.5 \mathrm{mM})$ and nonlabeled $(1.0 \mathrm{mM}) \mathrm{Fe}(\mathrm{III})$-chelates were prepared by adding, slowly, acidic Fe solutions (36 mM Fe or $9 \mathrm{mM}^{57} \mathrm{Fe}$ in $15 \% \mathrm{HCl}$, in $5 \%$ excess over the molar amount of chelating agent) over high-pH chelating agent solutions [13]. During the Fe addition, the solution $\mathrm{pH}$ was maintained in the range $6-8$ by adding $\mathrm{NH}_{4} \mathrm{OH}$. Then, solutions were neutralized (to $\mathrm{pH} 7.0$ with $\mathrm{NH}_{4} \mathrm{OH}$ and $\mathrm{HCl}$ ), equilibrated overnight in the dark and at room temperature, filtered through a $0.45 \mu \mathrm{m}$ PVDF membrane and finally made up to volume with Milli-Q water. Stock solutions of ${ }^{57} \mathrm{Fe}-$ labeled and nonlabeled $\mathrm{Fe}(\mathrm{III})$-chelates were stored in the dark at $4{ }^{\circ} \mathrm{C}$. Iron(III)chelate standard solutions of concentrations lower than $100 \mu \mathrm{M}$ were prepared daily from the stocks.

\section{Agricultural Matrices}

To validate the method, recovery assays were carried out for each Fe(III)-chelate using four agricultural matrices (nutrient solution, irrigation water, soil solution, and plant xylem exudate). The nutrient solution matrix was half-strength Hoagland nutrient solution [23] supplemented with $1 \mathrm{~g}^{-1} \mathrm{CaCO}_{3}$, without Fe, $\mathrm{pH}$ 7.2. Irrigation water was sampled from the "Bardenas" irrigation channel, which irrigates a large agricultural area in Aragón, Northern Spain. Main irrigation water characteristics were $\mathrm{pH} 8.5,0.35 \mathrm{dS} \mathrm{m}^{-1}$ electrical conductivity and $1.33,2.15,0.42,0.03,0.44,2.36,0.42$, $0.61 \mathrm{mg} \cdot 1^{-1}$ of $\mathrm{Ca}^{2+}, \mathrm{Mg}^{2+}, \mathrm{Na}^{+}, \mathrm{K}^{+}, \mathrm{CO}_{3}{ }^{2-}, \mathrm{HCO}_{3}{ }^{-}$, $\mathrm{SO}_{4}{ }^{2-}$, and $\mathrm{Cl}^{-}$, respectively. A saturated paste soil solution was obtained after water incubation of a soil sampled in a peach orchard located in Alcañiz (Teruel, Spain). Main soil characteristics were silt sandy texture, $\mathrm{pH}$ in water $8.0,30.5 \%$ total $\mathrm{CaCO}_{3}$ and $0.8 \%$ organic matter. Plant xylem exudates were isolated from commercial peach trees grown in the field, following the Schölander chamber method [24]. All agricultural matrices were filtered through a $0.45 \mu \mathrm{m}$ PVDF filter previously to their use.

\section{Commercial Fertilizers}

Eight commercial fertilizers, containing at least a synthetic Fe(III)-chelate, were analyzed. The following compounds were used: product $\mathrm{A}$, containing $\mathrm{Fe}(\mathrm{III})-$ EDTA and $13 \%$ soluble $\mathrm{Fe}$; product $\mathrm{B}$, containing Fe(III)-DTPA and $0.3 \%$ soluble Fe; product C, containing Fe(III)-HEDTA and 4.1\% soluble Fe; products D, E, and $\mathrm{F}$, containing $\mathrm{Fe}(\mathrm{III})$-EDDHA and $6 \%$ soluble $\mathrm{Fe}$; product $\mathrm{G}$, containing Fe(III)-EDDHMA and $6 \%$ soluble $\mathrm{Fe}$; product $\mathrm{H}$, containing $\mathrm{Fe}(\mathrm{III})$-EDDHSA and $6 \%$ soluble Fe. All soluble Fe contents indicated are those shown in the label and are given on a wt/wt basis. Fertilizer stock solutions (10 mM Fe) were prepared by dissolving the products in Milli-Q water. Solutions were filtered through a $0.45 \mu \mathrm{m}$ PVDF membrane and stored in the dark at $4{ }^{\circ} \mathrm{C}$.

\section{HPLC-ESI/MS(TOF) Analysis}

Analyses were carried out with a BioTOF II (Bruker Daltonics, Billerica, MA) coaxial multipass time-offlight (TOF) mass spectrometer equipped with an Apollo electrospray ionization source (ESI), and coupled to a Waters Alliance 2795 HPLC system (Waters, Milford, MA). The resolution of the mass spectrometer (TOF) detector used is higher than 10,000 FWHM (full width at half-maximum height).

The BioTOF II was operated with endplate and spray tip potentials of 2.8 and $3.3 \mathrm{kV}$, respectively, in negative 
ion mode, and of 3.5 and $4.0 \mathrm{kV}$, respectively, in positive ion mode. Drying gas $\left(\mathrm{N}_{2}\right)$ pressure was kept at 30 psi. Nebulizer gas $\left(\mathrm{N}_{2}\right)$ pressure was kept at 30 and $60 \mathrm{psi}$ in ESI/MS and LC-ESI/MS experiments, respectively. The mass axis was calibrated using Li-formate adducts in negative ion mode and a mixture of $1 \mu \mathrm{M}$ leucine-enkephaline, $5 \mu \mathrm{M}$ glutathione and $20 \mu \mathrm{M}$ methionine in positive ion mode. Spectra were acquired in the mass/charge ratio $(\mathrm{m} / \mathrm{z})$ range $100-800$.

To optimize the MS signal, direct injection of $10-\mu \mathrm{M}$ solutions of all $\mathrm{Fe}(\mathrm{III})$-chelates were carried out using a syringe pump (Cole-Parmer Instrument, Vernon Hills, IL) operated at $2 \mu \mathrm{l} \mathrm{min}^{-1}$. Optimal parameter values after tuning included negative polarity, orifice voltage value of $120 \mathrm{~V}$, and drying gas temperature of $200^{\circ} \mathrm{C}$. These parameters were chosen to maximize all signals without compromising the detection of any of the analytes.

High-performance liquid chromatography was performed with a Waters Alliance 2795 HPLC system (Waters) equipped with on-line degasser, autosampler module and column oven. Different chromatographic conditions were tested, and those described below were the best to obtain (1) the best possible MS signal for all analytes in the shorter analysis time, (2) the best possible separation between analytes having the same $\mathrm{m} / \mathrm{z}$, and (3) no changes in $\mathrm{Fe}(\mathrm{III})$-complexation during separation. The column used was an analytical HPLC column (Symmetry C18, $15 \mathrm{~cm} \times 2.1 \mathrm{~mm}$ i.d., $5 \mu \mathrm{m}$ spherical particle size, Waters) protected by a guard column (Symmetry C18, $10 \mathrm{~mm} \times 2.1 \mathrm{~mm}$ i.d., $3.5 \mu \mathrm{m}$ spherical particle size, Waters). Autosampler and column temperatures were 6 and $30^{\circ} \mathrm{C}$, respectively. Injection volume was $50 \mu \mathrm{l}$ and flow rate was $100 \mu \mathrm{l}$ $\min ^{-1}$. The mobile phase was built using three solvents: A (Milli-Q water), B (methanol), and C (20 mM ammonium acetate in Milli-Q water, $\mathrm{pH}$ 6.0). The initial conditions of the gradient program $(93 \% \mathrm{~A}, 2 \% \mathrm{~B}$, and $5 \% \mathrm{C}$ ) were held for $3 \mathrm{~min}$, followed by a linear gradient to $40 \% \mathrm{~A}, 55 \% \mathrm{~B}$, and $5 \% \mathrm{C}$ until $7 \mathrm{~min}$, and an isocratic step with the latter composition until $17 \mathrm{~min}$. Then, to return to the initial conditions, a new linear gradient to $93 \% \mathrm{~A}, 2 \% \mathrm{~B}$, and $5 \% \mathrm{C}$ was run until $20 \mathrm{~min}$, followed by a $10 \mathrm{~min}$ re-equilibration with the same mobile phase composition. The HPLC apparatus was coupled to the ESI/(TOF) mass spectrometer through a $125 \mu \mathrm{m}$ i.d. PEEK tube (Upchurch Scientific, Oak Harbor, WA).

The system was controlled with the software packages BioTOF (version 2.2, Bruker Daltonics) and HyStar (version 2.3, Bruker DaltoniK, Bremen, Germany). Data were processed with Data Analysis software (version 3.2, Bruker DaltoniK).

Validation was carried out by obtaining calibration curves (in each case corrected by using the corresponding ${ }^{57} \mathrm{Fe}$-labeled, $\mathrm{Fe}(\mathrm{III})$-chelate as an internal standard), limits of detection [LODs, signal/noise (S/N) ratio of 3], limits of quantification (LOQs, $\mathrm{S} / \mathrm{N}$ ratio of 10 ), intraand interday repeatability and recoveries in different

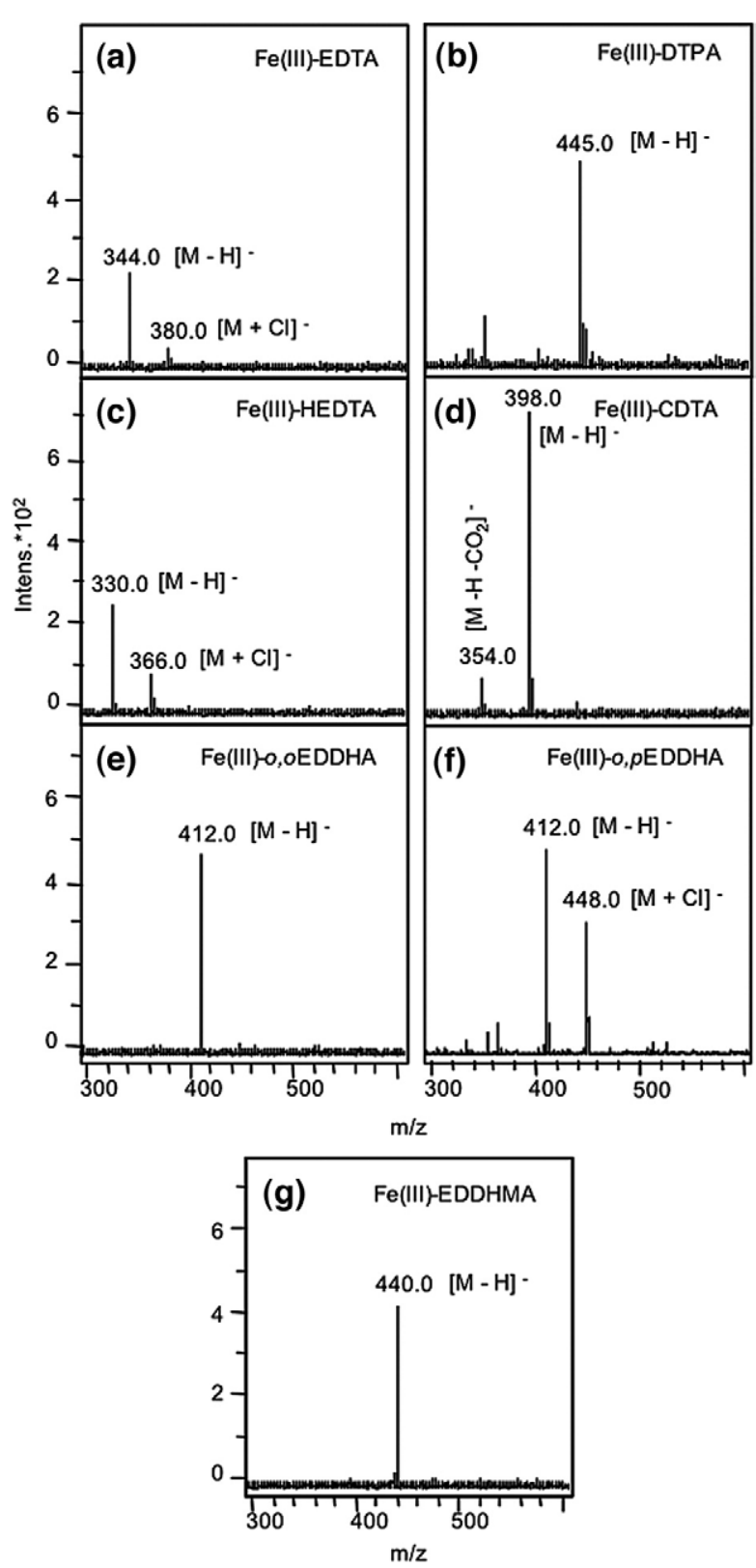

Figure 1. ESI/TOF mass spectra of $\mathrm{Fe}(\mathrm{III})$-EDTA (a), $\mathrm{Fe}(\mathrm{III})$ DTPA (b), Fe(III)-HEDTA (c), Fe(III)-CDTA (d), Fe(III)-o,oEDDHA (e), Fe(III)-o, $p$ EDDHA (f) and Fe(III)-EDDHMA (g) in negative ion mode. Data were acquired by injecting $5-\mu \mathrm{M}$ solutions of each analyte in water, except for $\mathrm{Fe}(\mathrm{III})-0, p \mathrm{EDDHA}$, where solution concentration was $20 \mu \mathrm{M}$.

matrices using standard techniques (for a complete description, see the Results section).

\section{Results}

\section{ESI/MS(TOF) Analysis}

Mass spectra of nonlabeled Fe(III)-chelate standard solutions were obtained under the ESI/MS conditions described in the Materials and Methods section (Figure 1). Major peaks found correspond to the ${ }^{56} \mathrm{Fe}$ signal of the $[\mathrm{M}-\mathrm{H}]^{-1}$ ions at $m / z$ values 344.0 for $\mathrm{Fe}(\mathrm{III})$-EDTA 


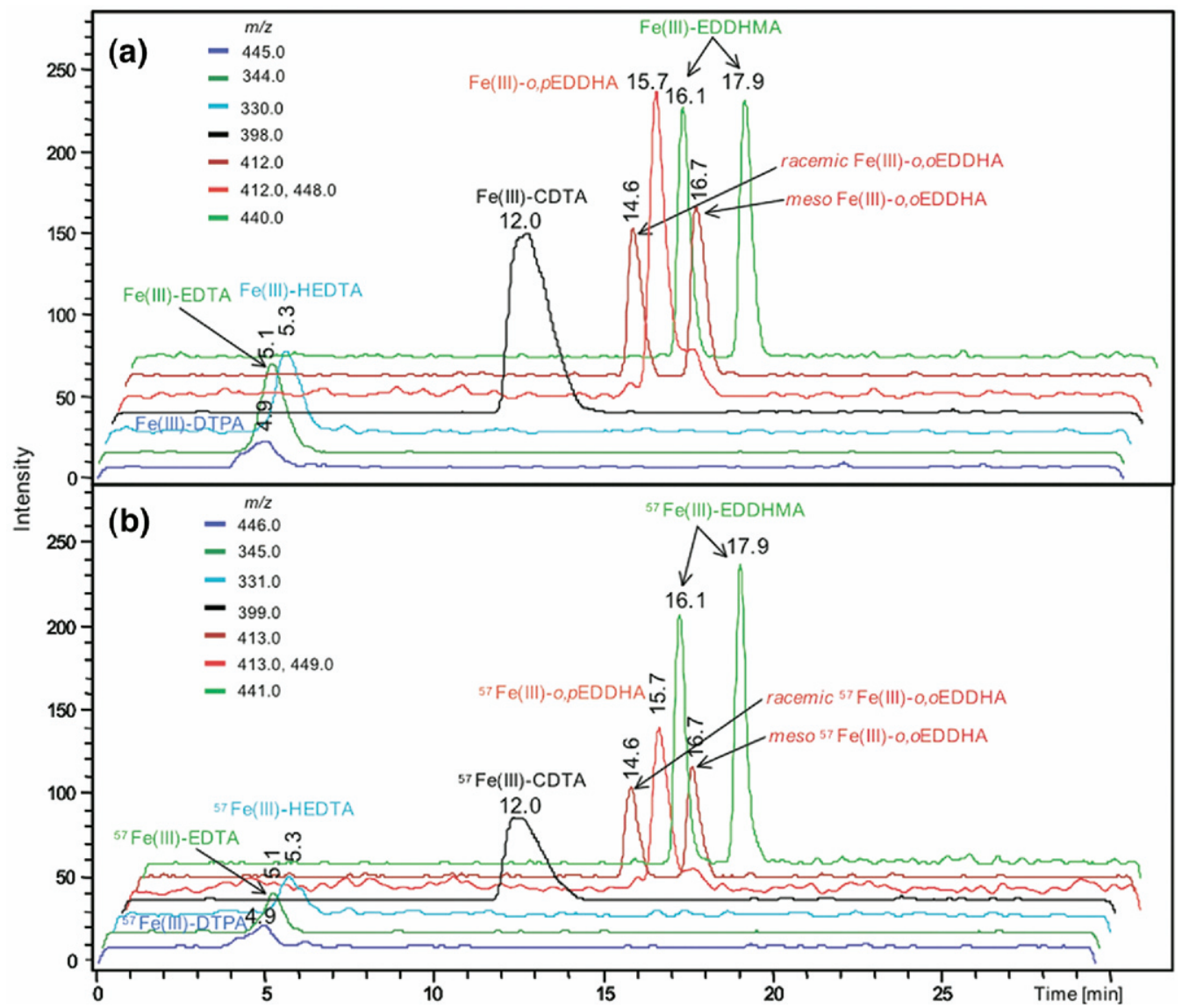

Figure 2. Chromatograms of simple solutions of nonlabeled (a) and the corresponding ${ }^{57} \mathrm{Fe}$-labeled (b) $\mathrm{Fe}$ (III)-chelates. Nonlabeled Fe(III)-chelates were at concentration of $20 \mu \mathrm{M}$, except for $\mathrm{Fe}(\mathrm{III})$ EDDHMA, used at a concentration of $10 \mu \mathrm{M} .{ }^{57} \mathrm{Fe}$-labeled Fe(III)-chelates were at concentration of 5 $\mu \mathrm{M}$, except for Fe(III)-DTPA, used at a concentration of $25 \mu \mathrm{M}$. Solutions were made in the mobile phase used at the start of the elution gradient ( $1 \mathrm{mM}$ ammonium acetate, $\mathrm{pH} 6.0,2 \%$ (vol/vol) methanol).

(Figure 1a), 445.0 for Fe(III)-DTPA (Figure 1b), 330.0 for Fe(III)-HEDTA (Figure 1c), 398.0 for Fe(III)-CDTA (Figure 1d), 412.0 for Fe(III)-o,oEDDHA, and Fe(III)-o,pEDDHA (Figure 1e and $\mathrm{f}$, respectively), and 440.0 for Fe(III)-EDDHMA (Figure 1g). Minor peaks at $m / z 380.0$ for Fe(III)-EDTA (Figure 1a), 366.0 for Fe(III)-HEDTA (Figure 1c), and $448.0 \mathrm{~m} / \mathrm{z}$ for Fe(III)-o, $p$ EDDHA (Figure 1f) correspond to the ${ }^{56} \mathrm{Fe}$ signal of the chloride adduct $[\mathrm{M}+\mathrm{Cl}]^{-1}$ ions. Also, a minor peak at $354.0 \mathrm{~m} / \mathrm{z}$ for $\mathrm{Fe}(\mathrm{III})$-CDTA (Figure 1d) is attributable to the ${ }^{56} \mathrm{Fe}$ signal of the monodecarboxylation of the analyte $[\mathrm{M}-$ $\left.\mathrm{H}-\mathrm{CO}_{2}\right]^{-1}$. In the positive ion mode, major peaks found in the MS spectra were at $m / z$ 346.0, 447.0, 332.0, $400.0,414.0,414.0$, and 442.0 corresponding to the ${ }^{56} \mathrm{Fe}$ signal of the $[\mathrm{M}+\mathrm{H}]^{+1}$ ions [for Fe(III)-EDTA, Fe(III)DTPA， Fe(III)-HEDTA， Fe(III)-CDTA， Fe(III)-o,oEDDHA, Fe(III)-o, $p$ EDDHA, and Fe(III)-EDDHMA, respectively, not shown]. Signals obtained in positive mode were slightly less intense (with a lower $\mathrm{S} / \mathrm{N}$ ) than those obtained in the negative ion mode (data not shown). Also, in the positive ion mode diluted acids (formic or acetic) had to be used to assist in the formation of positively charged gas-phase ions, which may compro- mise the stability of the Fe(III)-chelates. Therefore, the negative ion mode was chosen for further experiments.

\section{HPLC-ESI/MS(TOF) Analysis}

Analytes were separated with a solvent gradient at $\mathrm{pH}$ 6.0 in a $\mathrm{C}_{18}$ column, and mass spectra were acquired by $\mathrm{ESI} / \mathrm{MS}(\mathrm{TOF})$ in the $\mathrm{m} / \mathrm{z}$ range 100-800 during the whole chromatographic run, to obtain three dimensional (time, $m / z$, and intensity) chromatograms. For each $\mathrm{Fe}(\mathrm{III})$-chelate, the ion chromatogram was extracted at the $m / z$ of the ${ }^{56} \mathrm{Fe}$ isotope signal of the [M $\mathrm{H}]^{-1}$ molecular ion with a $\pm 0.2 \mathrm{~m} / \mathrm{z}$ precision range, except for Fe(III)-o,p-EDDHA, for which both the $m / z$ of the ${ }^{56} \mathrm{Fe}$ isotope signal of the $[\mathrm{M}-\mathrm{H}]^{-1}$ ion and that of the $\left[\mathrm{M}+\mathrm{Cl}^{-1}\right.$ ion were used $\left([\mathrm{M}-\mathrm{H}]^{-1}\right.$ and $[\mathrm{M}+$ $\mathrm{Cl}^{-1}$ were the two major ions in the Fe(III)-o,pEDDHA spectra). Results show that the HPLC-ESI/MS(TOF) method developed has high selectivity, allowing to resolve adequately all Fe(III)-chelates tested (Figure 2a). Retention times were $4.9 \mathrm{~min}$ for Fe(III)-DTPA, $5.1 \mathrm{~min}$ for Fe(III)-EDTA, $5.3 \mathrm{~min}$ for Fe(III)-HEDTA, $12.0 \mathrm{~min}$ for $\mathrm{Fe}(\mathrm{III})$-CDTA, $14.6 \mathrm{~min}$ for racemic $\mathrm{Fe}(\mathrm{III})-0, \mathrm{oED}$ - 
DHA, $15.7 \mathrm{~min}$ for $\mathrm{Fe}(\mathrm{III})-0, p$ EDDHA, $16.1 \mathrm{~min}$ for a first stereoisomer of $\mathrm{Fe}(\mathrm{III})$-EDDHMA, $16.7 \mathrm{~min}$ for meso $\mathrm{Fe}(\mathrm{III})-o, o$ EDDHA, and $17.9 \mathrm{~min}$ for a second stereoisomer of $\mathrm{Fe}(\mathrm{III})$-EDDHMA. The two peaks of $\mathrm{Fe}(\mathrm{III})$-EDDHMA are likely the racemic and meso forms, but they could not be assigned because of the lack of standards. Although they have the same $m / z$, the three $\mathrm{Fe}(\mathrm{III})$-EDDHA compounds (Fe(III)-o, $p$ EDDHA, racemic, and meso $\mathrm{Fe}(\mathrm{III})-0, o \mathrm{EDDHA}$ ) were adequately separated by HPLC. In all cases, isotopically-labeled $\left({ }^{57} \mathrm{Fe}\right)$ $\mathrm{Fe}(\mathrm{III})$-chelates co-eluted with their corresponding nonlabeled Fe(III)-chelates (Figure 2b). Times for separation and column stabilization were $\sim 20$ and $10 \mathrm{~min}$, respectively, thus leading to a total analysis run time of $30 \mathrm{~min}$ per sample.

\section{Validation of the HPLC-ESI/MS(TOF) Method}

The HPLC-ESI/MS(TOF) method was validated preparing solutions of $\mathrm{Fe}(\mathrm{III})$-chelate standards in initial mobile phase (1 mM ammonium acetate, $\mathrm{pH} 6.0,2 \%$ (vol/vol) methanol). Calibration curves corrected with internal standardization, LODs, intra- and interday repeatability, and recovery in agricultural matrices were measured.

Calibration curves corrected by internal standardization were obtained by analyzing solutions of standards in the ranges 2-50 $\mu \mathrm{M}$ (Fe(III)-EDTA and $\mathrm{Fe}$ (III)HEDTA), 5-50 $\mu \mathrm{M}$ (Fe(III)-DTPA), 0.5-50 $\mu \mathrm{M}$ (Fe(III)CDTA, and Fe(III)-o,pEDDHA), and 0.25-25 $\mu \mathrm{M}$ (racemic and meso Fe(III)-o,oEDDHA and Fe(III)-EDDHMA). The corresponding ${ }^{57} \mathrm{Fe}$-labeled $\mathrm{Fe}(\mathrm{III})$-chelates were used as internal standards. The peak area at the $\mathrm{m} / \mathrm{z}$ corresponding to the $[\mathrm{M}-\mathrm{H}]^{-1}$ of the ${ }^{57} \mathrm{Fe}$-chelate also include a small contribution of the nonlabeled $\mathrm{Fe}(\mathrm{III})$ chelate, because the natural isotopic composition of the analyte. To calculate the peak area ratios (sample area/ area of the internal standard) used in the calibration curves, the natural contribution of the nonlabeled analyte at the $\mathrm{m} / \mathrm{z}[\mathrm{M}-\mathrm{H}]^{-1}$ of the ${ }^{57} \mathrm{Fe}$-labeled internal standard was subtracted from the total peak area. In all cases, data were fitted to a linear regression ( $\mathrm{R}$ of 0.9962-0.9997) (Figure 3) indicating that the analytes could be determined in those ranges of concentrations.

LODs, defined as the analyte amounts giving an $\mathrm{S} / \mathrm{N}$ ratio of 3, were between 3 to $164 \mathrm{pmol}$, the lowest value corresponding to the second isomer of $\mathrm{Fe}(\mathrm{III})-\mathrm{ED}-$ DHMA and the highest to Fe(III)-DTPA (Table 1). Using a 50- $\mu$ l injection volume, these values are equivalent to analyte concentrations (in the injected solution) in the range 0.1-3.3 $\mu \mathrm{M}$. LOQs, defined as the amounts giving an $\mathrm{S} / \mathrm{N}$ ratio of 10, ranged from the lowest value of 14 pmol for the second isomer of Fe(III)-EDDHMA to the highest value of 945 pmol for Fe(III)-DTPA (Table 1).

The intraday repeatability of the HPLC-ESI/ MS(TOF) method was assessed from six consecutive chromatographic runs, using two levels of concentration for each analyte: 10 and $50 \mu \mathrm{M}$ for Fe(III)-EDTA, $\mathrm{Fe}(\mathrm{III})$-HEDTA, and Fe(III)-o,pEDDHA, 20 and $75 \mu \mathrm{M}$ for Fe(III)-DTPA, 2 and $20 \mu \mathrm{M}$ for Fe(III)-CDTA, and 1 and $10 \mu \mathrm{M}$ for meso and racemic Fe(III)-o,oEDDHA and $\mathrm{Fe}(\mathrm{III})$-EDDHMA. The variation in retention time and peak area ratio was assessed for each analyte (Table 2). The interday repeatability of the method was also assessed, by analyzing the same standard solution for six consecutive days (Table 2). The relative standard deviation (RSD) for peak retention time always was lower than $1.3 \%$ in the intraday test and $1.4 \%$ in the interday test. The RSD for peak area ratio was in the range $2.4-8.6 \%$ in the intraday test and $4.1-10.6 \%$ in the case of the interday test.

Recovery assays were carried out for each Fe(III)chelate by spiking four different agricultural matrices (nutrient solution, irrigation water, soil solution, and plant xylem exudate) with known amounts of each nonlabeled Fe(III)-chelate, using in each case the corresponding ${ }^{57} \mathrm{Fe}$-labeled $\mathrm{Fe}$ (III)-chelate as an internal standard. Representative chromatograms for the analysis of $\mathrm{Fe}(\mathrm{III})-0, \mathrm{oEDDHA}$ in agricultural matrices are shown in Figure 4. All Fe(III)-chelates had similar retention times in agricultural matrices than in simple solutions. Analyte recoveries found were in the ranges $92-101 \%$ for nutrient solution, $89-102 \%$ for irrigation water, 82 $100 \%$ for soil solution, and $70-111 \%$ for plant xylem exudate, respectively (Table 3). Recoveries depended on the analyte, with Fe(III)-EDTA and Fe(III)-DTPA showing the lowest recoveries (average values 87 and $88 \%$, respectively, for all agricultural matrices used) and on the agricultural matrices tested, with the lowest recoveries found for soil solution and plant xylem exudate, with average recovery values 90 and $91 \%$, respectively (average of all analytes).

\section{Analysis of Fertilizers}

Chromatograms of commercial fertilizers containing two of the most common Fe(III)-chelates, Fe(III)-EDTA and $\mathrm{Fe}(\mathrm{III})-\mathrm{EDDHA}$, are presented in Figure $5 \mathrm{a}$ and $\mathrm{b}$, respectively. The analysis of a Fe(III)-EDTA commercial fertilizer showed a peak with $\mathrm{m} / \mathrm{z} 344.0$ at $5.1 \mathrm{~min}$, corresponding to the ${ }^{56} \mathrm{Fe}$ signal of the $[\mathrm{M}-\mathrm{H}]^{-1}$ ion of this chelate (Figure 5a). The chromatogram of a Fe(III)EDDHA commercial fertilizer showed three peaks, all of them with $m / z 412.0$, corresponding to ${ }^{56} \mathrm{Fe}$ signal of the $[\mathrm{M}-\mathrm{H}]^{-1}$ ion of racemic and meso $\mathrm{Fe}(\mathrm{III})-0, o \mathrm{ED}$ DHA and Fe(III)-o,pEDDHA, at retention times of 14.6, 16.7, and 15.7 min (Figure 5b). A zoomed mass spectra at the retention time of the meso Fe(III)-o,oEDDHA is presented in the inset of Figure $5 b$, as an example of how the MS technique used can resolve the peaks for the different $\mathrm{Fe}$ isotopes $\left({ }^{54} \mathrm{Fe}-,{ }^{56} \mathrm{Fe}-,{ }^{57} \mathrm{Fe}-0, o\right.$ EDDHA) corresponding to the $[\mathrm{M}-\mathrm{H}]^{1-}$ ions.

The amounts of $\mathrm{Fe}(\mathrm{III})$-chelates found in the commercial fertilizers were in the range $0.3-10.5 \%(\mathrm{wt} / \mathrm{wt})$ (Table 4). These values account for $81,107,47,64,88,62$, and $57 \%$ of the soluble Fe contents declared in the label for products A, B, C, D, E, F, and G, respectively. For fertilizers containing $\mathrm{Fe}(\mathrm{III})$-EDDHA or $\mathrm{Fe}$ (III)-ED- 


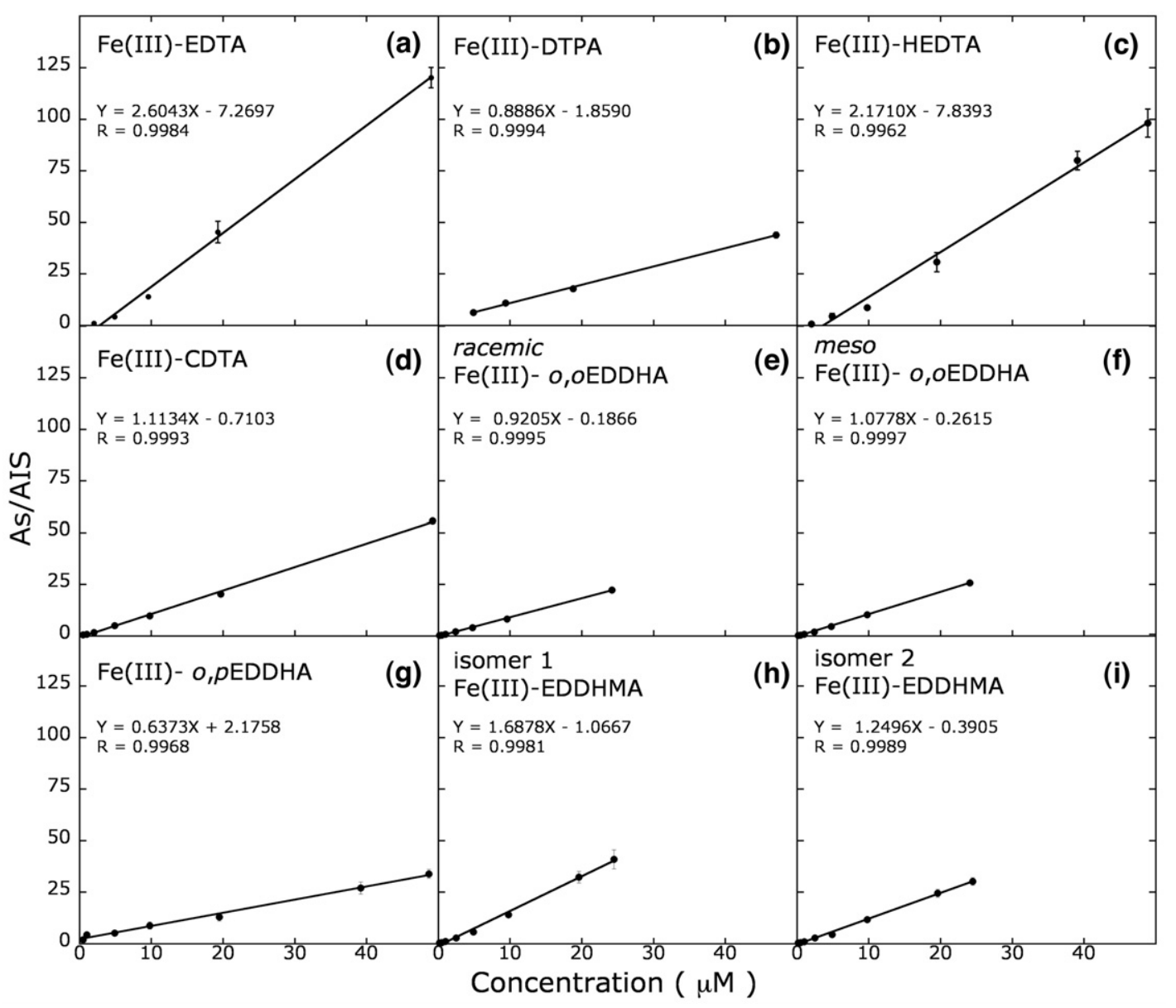

Figure 3. Calibration curves of Fe(III)-EDTA (a), Fe(III)-DTPA (b), Fe(III)-HEDTA (c), Fe(III)-CDTA (d), racemic Fe(III)-o,oEDDHA (e), meso Fe(III)-o,oEDDHA (f), Fe(III)-o, $p$ EDDHA (g), isomer 1 of Fe(III)EDDHMA (h), and isomer 2 of Fe(III)-EDDHMA (i) obtained by plotting the peak area ratio (sample area/area of the internal standard; As/AIS; Y-axis) versus the Fe(III)-chelate concentration injected. Internal standards were at a concentration of $5 \mu \mathrm{M}$, except for ${ }^{57} \mathrm{Fe}(\mathrm{III})$-DTPA, used at a concentration of $25 \mu \mathrm{M}$. Solutions were made in the mobile phase used at the start of the elution gradient $(1 \mathrm{mM}$ ammonium acetate, $\mathrm{pH} 6.0,2 \%$ (vol/vol) methanol). Bars are SE for triplicate measurements.

DHMA, the chelated Fe contents found compare well with data obtained using the European community official method of analysis [25] in a study analyzing 110

Table 1. Limits of detection (LOD) and quantification (LOQ) for several synthetic Fe(III)-chelates used as fertilizers

\begin{tabular}{lcc}
\hline \multicolumn{1}{c}{ Analyte } & LOD $(\mathrm{pmol})^{\mathrm{a}}$ & LOO $(\mathrm{pmol})^{\mathrm{b}}$ \\
\hline \hline Fe(III)-EDTA & 123 & 328 \\
Fe(III)-DTPA & 164 & 945 \\
Fe(III)-HEDTA & 87 & 295 \\
Fe(III)-CDTA & 10 & 50 \\
Fe(III)-o,oEDDHA & & \\
$\quad$ racemic & 4 & 19 \\
$\quad$ meso & 4 & 19 \\
Fe(III)- $o, p E D D H A$ & 4 & 17 \\
Fe(III)-EDDHMA & & \\
$\quad$ Isomer 1 & 5 & 17 \\
Isomer 2 & 3 & 14 \\
\hline
\end{tabular}

aLOD, defined as the analyte amount giving a signal/noise $(\mathrm{S} / \mathrm{N})$ ratio of 3.

bLO, defined as the analyte amount giving an $\mathrm{S} / \mathrm{N}$ ratio of 10 .
Fe(III)-EDDHA and $5 \mathrm{Fe}(\mathrm{III})$-EDDHMA fertilizers (all of them declaring a $6 \%$ soluble Fe content, commercialized in Spain in the years 2003 and 2004). The mean for chelated Fe content of the three Fe(III)-EDDHA products analyzed in this study (3.5\%) is slightly lower than the mean $(4.0 \%)$ obtained using the official method [26]. The chelated Fe content value (3.4\%) obtained using the HPLC-ESI/MS(TOF) method in the only Fe(III)-EDDHMA fertilizer analyzed is somewhat lower than the mean value $(4 \%)$ obtained using the official method [26].

Commercial fertilizers containing $\mathrm{Fe}(\mathrm{III})$-EDDCHA and Fe(III)-EDDHSA were also analyzed. These fertilizers showed peaks at $4.1 \mathrm{~min}(\mathrm{~m} / \mathrm{z}$ 500.0; $\mathrm{Fe}$ (III)-EDDCHA) and $4.0 \mathrm{~min}(\mathrm{~m} / \mathrm{z}$ 572.0; Fe(III)-EDDHSA), both of them attributable to the corresponding ${ }^{56} \mathrm{Fe}$ signal of the $[\mathrm{M}-\mathrm{H}]^{-1}$ ions (Figure $5 \mathrm{c}$ and d). Since commercial standards of EDDHSA and EDDCHA are not available, accurate quantification of these compounds cannot be carried out yet. 
Table 2. Intraday $(\mathrm{n}=6)$ and interday $(\mathrm{n}=6)$ repeatability $(\mathrm{RSD} \%)$ of the HPLC-ESI/MS(TOF) method

\begin{tabular}{|c|c|c|c|c|c|}
\hline \multirow[b]{2}{*}{ Analyte } & \multirow[b]{2}{*}{ Concentration $(\mu \mathrm{M})$} & \multicolumn{2}{|c|}{ Intraday } & \multicolumn{2}{|c|}{ Interday } \\
\hline & & R.T. (min) & As/AIS & R.T. $(\min )$ & As/AIS \\
\hline \multirow[t]{2}{*}{ Fe(III)-EDTA } & 10 & 0.1 & 8.6 & 1.4 & 9.8 \\
\hline & 50 & 0.9 & 5.0 & 1.1 & 5.3 \\
\hline \multirow[t]{2}{*}{ Fe(III)-DTPA } & 20 & 1.3 & 5.6 & 1.2 & 6.8 \\
\hline & 75 & 1.1 & 2.5 & 0.8 & 4.1 \\
\hline \multirow[t]{2}{*}{ Fe(III)-HEDTA } & 10 & 0.9 & 3.0 & 0.9 & 5.7 \\
\hline & 50 & 0.8 & 2.4 & 1.3 & 4.3 \\
\hline \multirow[t]{2}{*}{$\mathrm{Fe}(\mathrm{III})-\mathrm{CDTA}$} & 2 & 0.6 & 6.2 & 0.6 & 10.6 \\
\hline & 20 & 0.4 & 4.9 & 0.8 & 8.3 \\
\hline \multicolumn{6}{|l|}{$\mathrm{Fe}(\mathrm{III})-o, o \mathrm{EDDHA}$} \\
\hline \multirow[t]{2}{*}{ racemic } & 1 & 0.6 & 6.6 & 0.4 & 10.2 \\
\hline & 10 & 0.9 & 5.9 & 0.6 & 9.8 \\
\hline \multirow[t]{2}{*}{ meso } & 1 & 0.1 & 7.4 & 0.3 & 9.4 \\
\hline & 10 & 0.3 & 4.8 & 0.4 & 8.3 \\
\hline \multirow[t]{2}{*}{$\mathrm{Fe}(\mathrm{III})-o, p \mathrm{EDDHA}$} & 10 & 0.3 & 8.2 & 1.3 & 8.9 \\
\hline & 50 & 0.1 & 7.9 & 1.0 & 10.2 \\
\hline \multicolumn{6}{|l|}{ Fe(III)-EDDHMA } \\
\hline \multirow[t]{2}{*}{ Isomer 1} & 1 & 0.3 & 4.4 & 0.2 & 6.2 \\
\hline & 10 & 0.5 & 5.2 & 0.3 & 7.4 \\
\hline \multirow[t]{2}{*}{ Isomer 2} & 1 & 0.0 & 3.6 & 0.3 & 6.0 \\
\hline & 10 & 0.3 & 5.5 & 0.4 & 6.3 \\
\hline
\end{tabular}

RSD, relative standard deviation; R.T., retention time; As/AIS, peak area ratios (sample area/area of the internal standard).

Solutions were made in mobile phase at the initial conditions of the elution gradient ( $1 \mathrm{mM}$ ammonium acetate, $\mathrm{pH} 6.0,2 \%$ (vol/vol) methanol) and contained $5 \mu \mathrm{M}$ of the corresponding ${ }^{57} \mathrm{Fe}$-labeled Fe(III)-chelate as an internal standard (except for Fe(III)-DTPA solution, which contained $25 \mu \mathrm{M}$ of $\left.{ }^{57} \mathrm{Fe}(\mathrm{III})-\mathrm{DTPA}\right)$.

\section{Discussion}

Synthetic $\mathrm{Fe}(\mathrm{III})$-chelates are extensively used as $\mathrm{Fe}$ fertilizers, both in high-value crops grown in the field and in soilless horticulture, making it thus necessary to have reliable methods to analyze these xenobiotic compounds in agricultural matrices. In this work, we have developed and validated an HPLC-ESI/MS(TOF) method capable of measuring the seven major synthetic $\mathrm{Fe}(\mathrm{III})$-chelates used as fertilizers, including $\mathrm{Fe}(\mathrm{III})$ EDTA, Fe(III)-DTPA, Fe(III)-HEDTA, Fe(III)-CDTA, $\mathrm{Fe}(\mathrm{III})-o, o$ EDDHA, Fe(III)-o, $p$ EDDHA, and Fe(III)-EDDHMA, in several agricultural matrices. The method involves separation by reverse phase HPLC, ionization by ESI, and highly selective detection of the analytes, using exact mass measurements with a TOF mass spectrometer.

This is the first time, to our knowledge, that $\mathrm{Fe}(\mathrm{III})$-EDTA, Fe(III)-DTPA, Fe(III)-HEDTA, Fe(III)CDTA, racemic Fe(III)-o,oEDDHA, meso $\mathrm{Fe}(\mathrm{III})-o, o \mathrm{ED}-$ DHA, Fe(III)-o,pEDDHA, and the two Fe(III)-EDDHMA stereoisomers are determined simultaneously and directly. The method represents significant advantages to traditional methods for the determination of synthetic $\mathrm{Fe}(\mathrm{III})$-chelates. First, the identification of analytes is unequivocal, based on its retention time, exact $\mathrm{m} / \mathrm{z}$ ratio, and $\mathrm{Fe}$ isotopic signature. Also, all compounds are measured directly and simultaneously under chromatographic conditions, preserving $\mathrm{Fe}(\mathrm{III})$-complexation occurring in the environmental matrices used, allowing for the determination of these compounds in complex mixtures and in a single run. All these features, along with the reasonably short (30 $\mathrm{min}$ ) analysis time required per sample and the fact that the determination can be carried out in different agricultural matrices (nutrient solution, irrigation water, soil solution, and plant xylem exudate) allow for the analysis of $\mu \mathrm{M}$ concentrations of synthetic Fe(III) fertilizers in the plant soil environment system.

The method developed has been validated for each analyte with respect to LODs, LOQs, calibration curves, reproducibility, and analyte recoveries, always using isotopically labeled standards. Overall sensitivity was good, with LODs between 3 and 164 pmol (corresponding to concentrations in the injected sample 0.1-3.3 $\mu \mathrm{M}$ ), a range much better than those found with other methods aimed to determine simultaneously several synthetic Fe(III)-chelates. For instance, an ion-pair HPLC method developed to determine five of the $\mathrm{Fe}(\mathrm{III})$-chelates studied here had LODs of $1790 \mathrm{pmol}$ for $\mathrm{Fe}(\mathrm{III})-o, o$ EDDHA and Fe(III)-EDDHMA (for the other three analytes, Fe(III)-EDTA, Fe(III)-DTPA, and Fe(III)HEDTA, LODs were not reported) [11]. A second ion-pair HPLC method aimed to determine five synthetic $\mathrm{Fe}(\mathrm{III})$-chelates was only capable to determine analyte concentrations above $8.9 \mu \mathrm{M}$ [13]. On the other hand, methods have been developed to determine individual $\mathrm{Fe}(\mathrm{III})$-chelates (often along with other analytes), and some of these had low LOD values, particularly for Fe(III)-EDTA. For instance, low LOD values $(0.02 \mu \mathrm{M})$ were obtained in a method designed to measure EDTA as Fe(III)-EDTA by HPLC-ESI/MS [19]; 


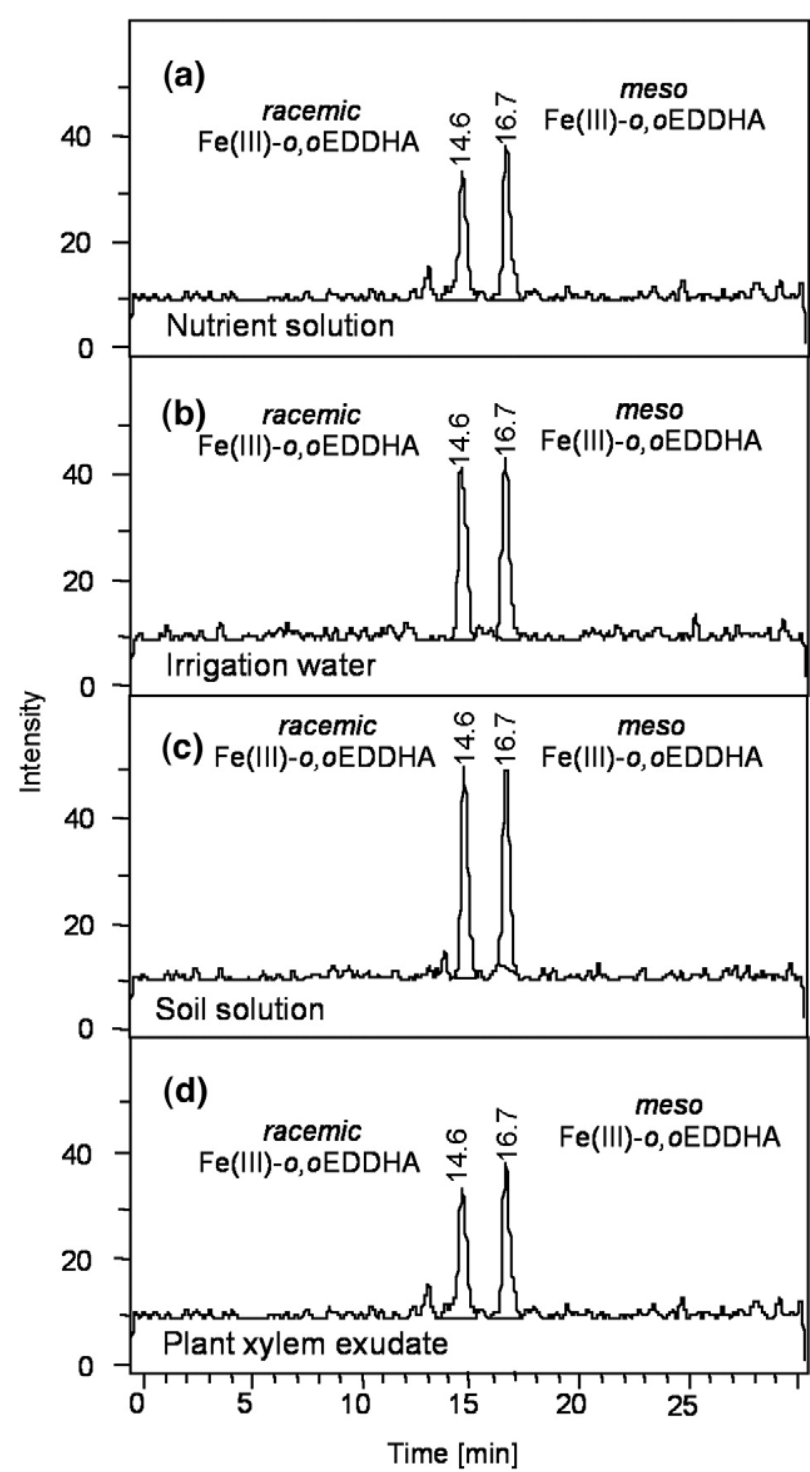

Figure 4. Chromatograms at $412.0 \mathrm{~m} / \mathrm{z}$ of nutrient solution (a), irrigation water (b), soil solution (c), and plant xylem exudate (d) spiked with $10 \mu \mathrm{M}$ Fe(III)-o,oEDDHA. this value is lower than the $2.45 \mu \mathrm{M}$ Fe(III)-EDTA LOD obtained with our method. Very low LOD values for Fe(III)-EDTA (125-150 nM) were also obtained with a HPLC-ICP/MS method developed to determine various polycarboxylic chelators (including EDTA, CDTA, DTPA, and others) and their metal complexes, although LODs for Fe(III)-CDTA and Fe(III)-DTPA were not studied [15].

The most common Fe fertilizer used in fruit crops grown in calcareous soils, Fe(III)-o,oEDDHA, has been much less studied than Fe(III)-EDTA. For this compound, the LOD of our method $(0.08 \mu \mathrm{M})$ is better than the values found until now using HPLC and UV-Vis spectroscopy $(1.2 \mu \mathrm{M}$ in simple solutions and $60 \mu \mathrm{M}$ in soil solutions [27] and $263 \mu \mathrm{M}$ in plant tissue extracts [28]. Also, for Fe(III)-o, $p$ EDDHA, a little-studied compound whose use as fertilizer has been recently accepted by the new European community fertilizer regulation [29], the LOD obtained here $(0.07 \mu \mathrm{M})$ is lower than the $3.3 \mu \mathrm{M}$ LOD of the only (HPLC-Vis) method published until now [30].

The method repeatability for peak area, with RSD values of $\sim 5$ and $8 \%$ for intra- and interday experiments, compares well with HPLC-ESI/MS or HPLCICP/MS methods, although values are not as good as those obtained with methods using HPLC coupled to $\mathrm{UV}-\mathrm{Vis}$ spectroscopy. For instance, the values of Fe(III)-EDTA repeatability, in the range 5-10\%, are in line with values of $5-6 \%$ found with HPLC-ICP/MS [15] and 2\% obtained using HPLC-ESI/MS [19]. Methods using HPLC coupled to UV-Vis spectroscopy, however, had repeatability values of $\sim 1 \%$ (Fe(III)-EDTA and Fe(III)-DTPA [9]; Fe(III)-o,oEDDHA [27]; Fe(III)- $0, p$ EDDHA [30], values lower than those found here for the same compounds, which are in the range $3-10 \%$. The recoveries obtained by spiking agricultural matrices were good, and only the recovery for Fe(III)-EDTA in all agricultural matrices tested was relatively low, in the range $83-92 \%$, compared with the $96 \%$ obtained for Fe(III)-EDTA in industrial effluents

Table 3. Recoveries (in \%) obtained for the nine different Fe(III)-chelates using different agricultural matrices

\begin{tabular}{lcccc}
\hline \multicolumn{1}{c}{ Analyte } & Nutrient solution & Irrigation water & Soil solution & Plant xylem exudate \\
\hline \hline Fe(III)-EDTA & $92.1 \pm 2.0$ & $88.9 \pm 2.5$ & $82.6 \pm 2.3$ & $82.8 \pm 1.8$ \\
Fe(III)-DTPA & $101.2 \pm 4.0$ & $100.2 \pm 5.7$ & $81.9 \pm 4.8$ & $70.0 \pm 5.0$ \\
Fe(III)-HEDTA & $98.9 \pm 2.8$ & $101.7 \pm 3.0$ & $83.3 \pm 9.8$ & $96.9 \pm 0.9$ \\
Fe(III)-CDTA & $99.5 \pm 5.4$ & $94.0 \pm 5.0$ & $98.6 \pm 2.9$ & $110.9 \pm 9.9$ \\
Fe(III)-o,oEDDHA ${ }^{a}$ & $(94.8 \pm 3.0)$ & $(96.6 \pm 1.6)$ & $(91.6 \pm 1.1)$ & $(95.6 \pm 1.1)$ \\
racemic & $94.4 \pm 1.5$ & $99.5 \pm 2.3$ & $104.3 \pm 2.6$ & $95.7 \pm 4.4$ \\
meso & $94.6 \pm 6.2$ & $93.6 \pm 4.9$ & $78.8 \pm 1.6$ & $95.4 \pm 2.2$ \\
Fe(III)-o, $p E_{D D H A}$ & $100.5 \pm 1.3$ & $95.3 \pm 4.6$ & $91.9 \pm 2.0$ & $91.5 \pm 1.7$ \\
Fe(III)-EDDHMA & $(96.6 \pm 2.1)$ & $(93.5 \pm 2.3$ & $(99.9 \pm 5.4)$ & $(89.9 \pm 2.0)$ \\
Isomer 1 & $94.7 \pm 2.5$ & $97.6 \pm 3.6$ & $103.6 \pm 5.6$ & $86.9 \pm 1.5$ \\
Isomer 2 & $96.5 \pm 2.8$ & $89.9 \pm 1.3$ & $95.9 \pm 5.2$ & $92.5 \pm 2.6$ \\
\hline
\end{tabular}

Values are means $\pm \mathrm{SE}(\mathrm{n}=3)$.

The amounts spiked were $10 \mu \mathrm{M}$ of Fe(III)-EDTA, Fe(III)-CDTA, Fe(III)-o,oEDDHA, and Fe(III)-EDDHMA, and $50 \mu$ M of Fe(III)-DTPA, Fe(III)-HEDTA, and $\mathrm{Fe}(\mathrm{III})-0, p \mathrm{EDDHA}$.

aValues for Fe(III)-o,oEDDHA and Fe(III)-EDDHMA are presented for the racemic mixture and meso forms, and also for the average compound (values in parenthesis), assuming a $50 \%$ content of each form. 


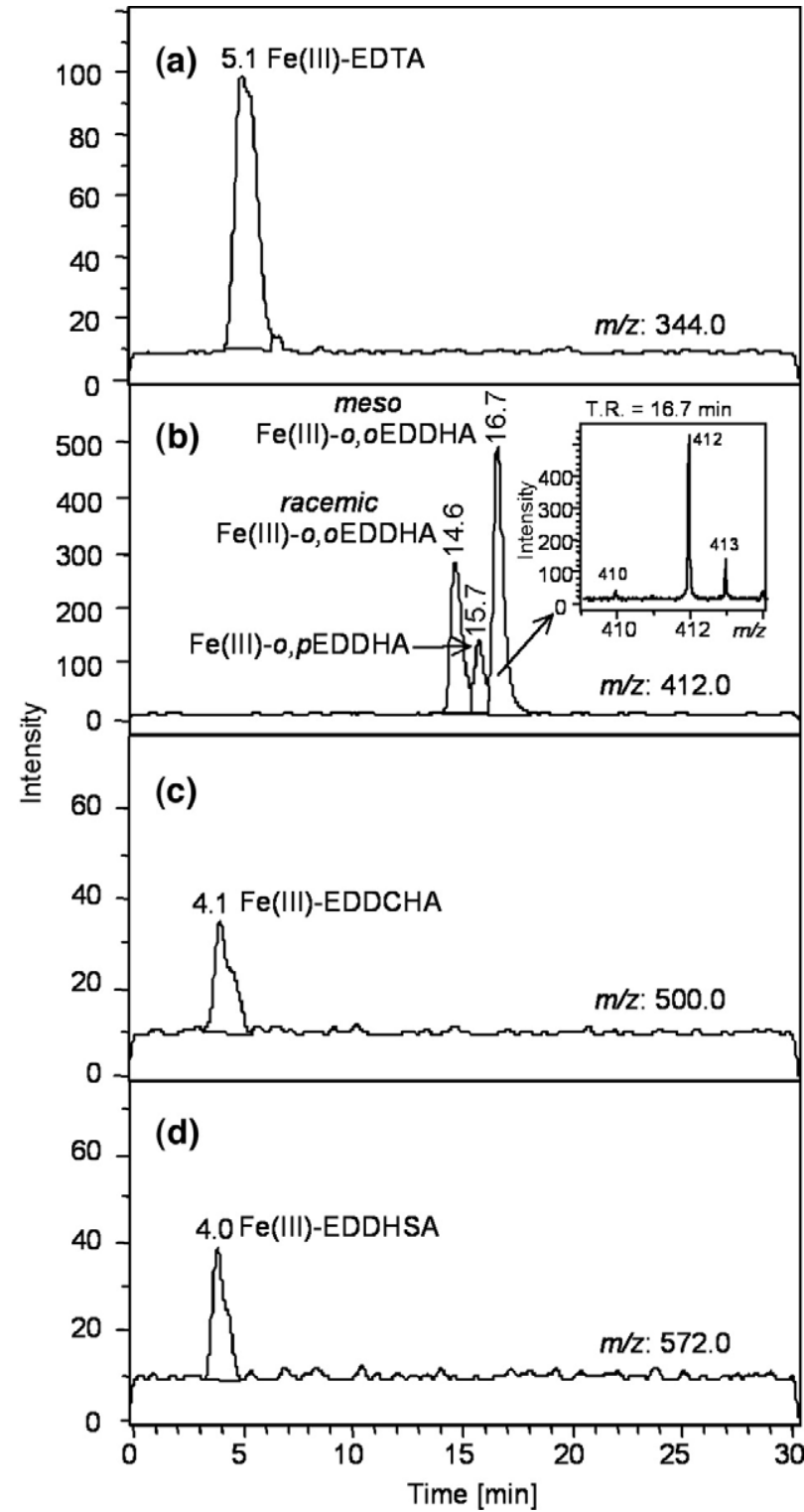

Figure 5. Chromatograms of commercial fertilizers. Fe(III)EDTA (a), Fe(III)-EDDHA (b), Fe(III)-EDDCHA (c), and Fe(III)EDDHSA (d) fertilizer solutions were at a concentration of 4.3, $10.6,18.3$, and $90.3 \mathrm{mg}$ product $\mathrm{l}^{-1}$, respectively, in the mobile phase used at the start of the elution gradient $(1 \mathrm{mM}$ ammonium acetate, $\mathrm{pH} 6.0,2 \%$ (vol/vol) methanol). The inset in (b) shows a zoom of the mass spectrum at a retention time of $16.7 \mathrm{~min}$ for the Fe(III)-EDDHA fertilizer analysis.

[19]. Recoveries for $\mathrm{Fe}(\mathrm{III})-0, \mathrm{oEDDHA}$ were in the range $79-104 \%$, similar to the $84-94 \%$ found by Bienfait et al. [28].

The method has wide possibilities of application, and it has been tested so far with different agricultural matrices (nutrient solution, irrigation water, soil solution, and plant xylem exudate) and with fertilizers, showing its suitability to perform analyses in a variety of studies. Chelated Fe contents obtained for fertilizers compares well with data obtained by using the European community official method of analysis by GarcíaMarco [26]. In addition to Fe(III)-EDTA, Fe(III)-DTPA,
Table 4. Contents of Fe(III)-chelates found in commercial fertilizer products using the HPLC-ESI/MS(TOF) method

\begin{tabular}{|c|c|c|}
\hline Product & Fe(III)-chelate & $\begin{array}{l}\text { Content (g chelated } \mathrm{Fe} / 100 \mathrm{~g} \\
\text { product) }\end{array}$ \\
\hline A & Fe(III)-EDTA & $10.50 \pm 0.65$ \\
\hline B & Fe(III)-DTPA & $0.32 \pm 0.01$ \\
\hline C & Fe(III)-HEDTA & $1.91 \pm 0.39$ \\
\hline \multicolumn{3}{|c|}{ 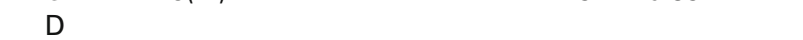 } \\
\hline & $\mathrm{Fe}(\mathrm{III})-o, o \mathrm{EDDHA}$ & $2.94 \pm 0.15$ \\
\hline & $\mathrm{Fe}(\mathrm{III})-o, p \mathrm{EDDHA}$ & $0.91 \pm 0.05$ \\
\hline \multicolumn{3}{|c|}{ - } \\
\hline & $\mathrm{Fe}(\mathrm{III})-o, o \mathrm{EDDHA}$ & $4.32 \pm 0.21$ \\
\hline & $\mathrm{Fe}(\mathrm{III})-o, p \mathrm{EDDHA}$ & $0.94 \pm 0.07$ \\
\hline \multicolumn{3}{|c|}{ 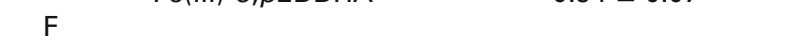 } \\
\hline & $\mathrm{Fe}(\mathrm{III})-o, o \mathrm{EDDHA}$ & $3.13 \pm 0.14$ \\
\hline & $\mathrm{Fe}(\mathrm{III})-o, p \mathrm{EDDHA}$ & $0.58 \pm 0.08$ \\
\hline G & Fe(III)-EDDHMA & $3.41 \pm 0.11$ \\
\hline
\end{tabular}

Values are means $\pm S E(n=3)$.

Fe(III)-HEDTA, Fe(III)-CDTA, racemic $\mathrm{Fe}(\mathrm{III})-o, o \mathrm{ED}$ DHA, meso Fe(III)-o,oEDDHA, Fe(III)-o,pEDDHA, racemic Fe(III)-EDDHMA, and meso Fe(III)-EDDHMA, the chelates Fe(III)-EDDHSA and Fe(III)-EDDCHA (putatively assigned to the peaks at $4.0 \mathrm{~min}$ with a $572.0 \mathrm{~m} / \mathrm{z}$ and $4.1 \mathrm{~min}$ with a $500.0 \mathrm{~m} / \mathrm{z}$ ) could also be analyzed, therefore providing a tool for a comprehensive study of the fate, action mechanisms, and possible environmental side effects of synthetic Fe(III)-chelate fertilizers. Furthermore, the method also seems to be suitable to analyze synthetic chelates of metals other than Fe (results not shown).

In summary, the method developed permits the direct and simultaneous analysis of the major synthetic $\mathrm{Fe}(\mathrm{III})$-chelates used as fertilizers with extreme selectivity, high sensitivity, and sufficient reproducibility. The rapidity of the analysis allows for a high analysis throughput. Furthermore, the resolution of the mass spectrometer used can give information on isotopic distribution (see inset in Figure 5b), allowing its use as a tool in metabolic studies with stable isotopes. For instance, using synthetic Fe(III)-chelates labeled with low-abundance Fe stable isotopes $\left({ }^{54} \mathrm{Fe},{ }^{57} \mathrm{Fe}\right.$ and $\left.{ }^{58} \mathrm{Fe}\right)$, the uptake pathways of these compounds applied to different parts of the plant at the same time (e.g., foliar, trunk, soil applied) can be followed. Also, the uptake rates of different synthetic $\mathrm{Fe}(\mathrm{III})$-chelates can be studied.

\section{Acknowledgments}

This work was supported by the Spanish Ministry of Science and Education (MEC) (projects AGL2003-1999 and AGL2004-0194, cofinanced with FEDER) and the Commission of European Communities (project Isafruit). IO and AA-F were supported by a CONAID-DGA predoctoral fellowship and a "Ramón y Cajal" research contract from the Spanish MEC, respectively. Acquisition of the HPLC-MS(TOF) apparatus was cofinanced with FEDER. The authors acknowledge I. Tacchini for skillful technical assistance and Dr. F. Morales for critical reading of the manuscript. The authors thank Dr. J. J. Lucena (Universidad Autónoma de Madrid, Spain) and Dr. J. M. García-Mina (Universidad de Navarra, Spain) 
for their generous gift of chemicals. The authors also thank two anonymous reviewers for helpful suggestions.

\section{References}

1. Shenker, M.; Chen, Y. Increasing Iron Availability to Crops: Fertilizers, Organo-Fertilizers, and Biological Approaches. Soil Sci. Plant Nutr. 2005, 51, 1-17.

2. Hansen, N. C.; Hopkins, B. G.; Ellsworth, J. W.; Jolley, V. D. Iron Nutrition in Field Crops. In Iron Nutrition in Plants and Rizhospheric Microorganisms; Barton, L. L.; Abadía, J., Eds.; Springer: Dordrecht, The Netherlands, 2006; pp 23-59.

3. Álvarez-Fernández, A.; Paniagua, P.; Abadía, J.; Abadía, A. Effects of Fe Deficiency Chlorosis on Yield and Fruit Quality in Peach (Prunus persica L. Batsch). J. Agric. Food Chem. 2003, 51, 5738-5744.

4. Vasconcelos, M.; Grusak, M. A. Status and Future Developments Involving Plant Iron in Animal and Human Nutrition. In Iron Nutrition in Plants and Rizhospheric Microorganisms; Barton, L. L.; Abadía, J., Eds.; Springer: Dordrecht, The Netherlands, 2006; pp 1-22.

5. Lucena, J. J. Synthetic Iron Chelates to Correct Iron Deficiency in Plants. In Iron Nutrition in Plants and Rizhospheric Microorganisms; Barton, L. L.; Abadía, J., Eds., Springer: Dordrecht, The Netherlands, 2006; pp 103128 .

6. Nowack, B. Environmental Chemistry of Aminopolycarboxylate Chelating Agents. Environ. Sci. Technol. 2002, 36, 4009-4016.

7. Knepper, T. P. Synthetic Chelating Agents and Compounds Exhibiting Complexing Properties in the Aquatic Environment. Trac-Trends Anal. Chem. 2003, 22, 708-724.

8. Hill-Cottingham, D. G. Paper Chromatography of Some Complexes and Their Iron Chelates. J. Chromatogr. 1962, 8, 261-264.

9. Boxema, R. Analysis of Iron Chelates in Commercial Iron Fertilizers by Gel Chromatography. Z. Pflanzen. Bodenk. 1978, 142, 824-835.

10. Deacon, M.; Smyth, M. R.; Tuinstra, L. Chromatographic Separations of Metal Chelates Present in Commercial Fertilizers. I. Development of a Gel-Permeation Chromatographic Separation Method for the Identification of Metal-Chelates in Commercial Fertilizers. J. Chromatogr. A 1993, 657, 69-76.

11. Deacon, M.; Smyth, M. R.; Tuinstra, L. Chromatographic Separations of Metal Chelates Present in Commercial Fertilizers. II. Development of an Ion-Pair Chromatographic Separation for the Simultaneous Determination of the Fe(III) Chelates of EDTA, DTPA, HEEDTA, EDDHA and EDDHMA, and the $\mathrm{Cu}(\mathrm{II}), \mathrm{Zn}(\mathrm{II})$, and $\mathrm{Mn}(\mathrm{II})$ Chelates of EDTA. J. Chromatogr. A 1994, 659, 349-357.

12. Vandegucht, I. Determination of Chelating Agents in Fertilizers by Ion Chromatography. J. Chromatogr. A 1994, 671, 359-365.

13. Lucena, J. J.; Barak, P.; Hernández-Apaolaza, L. Isocratic Ion-Pair High Performance Liquid Chromatographic Method for the Determination of Various Iron(III) Chelates. J. Chromatogr. A 1996, 727, 253-264.

14. Lobinski, R.; Schaumloffel, D.; Szpunar, J. Mass Spectrometry in Bioinorganic Analytical Chemistry. Mass Spectrom. Rev. 2006, 25, 255-289.

15. Ammann, A. A. Speciation of Heavy Metals in Environmental Water by Ion Chromatography Coupled to ICP-MS. Anal. Bioanal. Chem. 2002, 372, $448-452$.
16. Ammann, A. A. Determination of Strong Binding Chelators and their Metal Complexes by Anion-Exchange Chromatography and Inductively Coupled Plasma Mass Spectrometry. J. Chromatogr. A 2002, 947 205-216.

17. Baron, D.; Hering, J. G. Analysis of Metal-EDTA Complexes by Electrospray Mass Spectrometry. J. Environ. Oual. 1998, 27, 844-850.

18. Collins, R. N.; Onisko, B. C.; McLaughlin, M. J.; Merrington, G. Determination of Metal-EDTA Complexes in Soil Solution and Plant Xylem by Ion Chromatography-Electrospray Mass Spectrometry. Environ. Sci. Technol. 2001, 35, 2589-2593.

19. Dodi, A.; Monnier, V. Determination of Ethylenediaminetetraacetic Acid at Very Low Concentrations by High-Performance Liquid Chromatography Coupled with Electrospray Mass Spectrometry. J. Chromatogr. A 2004, 1032, 87-92.

20. Knepper, T. P.; Werner, A.; Bogenschutz, G. Determination of Synthetic Chelating Agents in Surface and Waste Water by Ion ChromatographyMass Spectrometry. J. Chromatogr. A 2005, 1085, 240-246.

21. Cantera, R. G.; Zamarreño, A. M.; García-Mina, J. M. Characterization of Commercial Iron Chelates and their Behavior in an Alkaline and Calcareous Soil. J. Agric. Food Chem. 2002, 50, 7609-7615.

22. Garcı-Marco, S.; Cremonini, M. A.; Esteban, P.; Yunta, F.; HernándezApaolaza, L.; Placucci, G.; Lucena, J. J. Gradient Ion-Pair Chromatographic Method for the Determination of Iron N,N'-Ethylenediaminedi-(2-Hydroxy-5-Sulfophenylacetate) by High Performance Liquid Chromatography-Atmospheric Pressure Ionization Electrospray Mass Spectrometry. J. Chromatogr. A 2005, 1064, 67-74.

23. Zaharieva, T. B.; Gogorcena, Y.; Abadía, J. Dynamics of Metabolic Responses to Iron Deficiency in Sugar Beet Roots. Plant Sci. 2004, 166, 1045-1050.

24. Larbi, A.; Morales, F.; Abadía, J.; Abadía, A. Effects of Branch Solid Fe Sulphate Implants on Xylem Sap Composition in Field-Grown Peach and Pear: Changes in Fe, Organic Anions and pH. J. Plant Physiol. 2003, $160,1473-1481$.

25. European Committee for Standardization. 2001. Determination of Chelating Agents in Fertilizers by Ion Chromatography. Part II: EDDHA and EDDHMA. Ref. No. EN 13368-2:2001 E.

26. García-Marco, S. Quality of Synthetic $\mathrm{Fe}^{3+}$-Chelates Spanish Market $\left(\mathrm{EDDHA} / \mathrm{Fe}^{3+}, \mathrm{EDDHMA} / \mathrm{Fe}^{3+}\right.$, and EDDHSA $\left./ \mathrm{Fe}^{3+}\right)$. Scientific Contributions to the Legal Framework for Ferric-Chelate Fertilizers: Chromatographic Analysis; Agronomic Efficiency of o, $\mathrm{p}-\mathrm{EDDHA} / \mathrm{Fe}^{3+} ; \mathrm{Ph} . \mathrm{D}$. Thesis of the Autonoma University of Madrid, Spain, 2005; pp 95-115.

27. Barak, P.; Chen, Y. Determination of FeEDDHA in Soils and Fertilizers by Anion-Exchange Chromatography. Soil Sci. Soc. Am. J. 1987, 51, 893-896.

28. Bienfait, H. F.; García-Mina, J.; Zamarreño, A. M. Distribution and Secondary Effects of EDDHA in Some Vegetable Species. Soil Sci. Plant Nutr. 2004, 50, 1103-1110.

29. Regulation (EC) No. 2003/2003 of the European Parliament and of the Council of 13 October 2003 Relating to Fertilizers. Official J. Eur. Union 2003, L304, 1-194.

30. García-Marco, S.; Torreblanca, A.; Lucena, J. J. Chromatographic Determination of Fe Chelated by Ethylenediamine- $\mathrm{N}-(o-H y d r o x y p h e n y l a c-$ etic)-N'-( $p$-Hydroxyphenylacetic) Acid in Commercial EDDHA/Fe ${ }^{3+}$ Fertilizers. J. Agric. Food Chem. 2006, 54, 1380-1386. 